\title{
- XXIV -
}

IB a ib Deutfice Berfaffungzgefdidte. Rie! 1844. 2 Th. 8.

- Dad alte Redt Der Gnlifdjen fronten. Riel 1846. 8.

- Heber die altbeatidie 5ufe. Böttingen 1854. 4.

- Heber die Anfänge der Baffaldität. Böttingen 18j6. 4.

Hale Diefe Berke find Durd igre ftrenge uno umfoffento Duellenfor:

fđuung febr. aub̧gezeidinet.

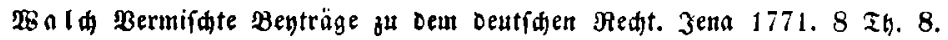

2B allraf Beiträge zur Bef́didte der Staot Rüln. SPüln 1818. 8.

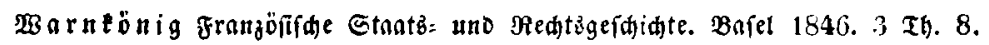

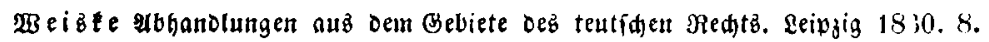

- Die Brumblagen der früheren Berfaffung Deutídanob. Leipjig 18.30. 8.

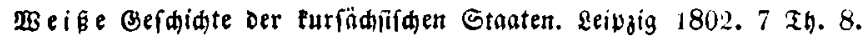

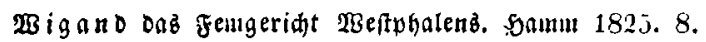

- Die Dienfte, igre Entfehung, Natur, artent uno @diffíale. Samm 1828. 8.

- 2Beglar'fae Beiträge. Weg̨lar 1840. 3 Th. 8.

28 illoa dả Bildentwefen in Mittelalter. Salle 18:31. 8.

- oab Etrafredt ber Germaneat. Şalle 1812. 8.

(W o l.kern) Historia Norimbergensis diplomatica. Nüurnberg 1738. 8.

F. von $\mathfrak{B}$ orittgen Beiträge zur Befdidte Dez Deutiden Gtrafredtz. Berlin 18 ;6. 8. Snt über roidtige punfte neue ridtige anjidteit begründet.

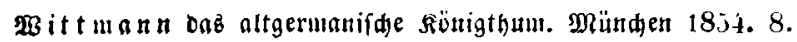

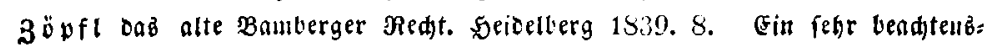
rortbea uno leb̆rreidez $\mathfrak{2 B e r k}$

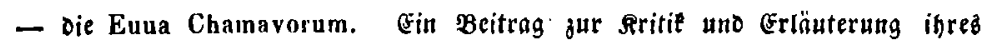
Tertę. Seidelberg $18 j 0$. 8.

\section{$\mathfrak{B e r b} \mathfrak{c}\{\mathfrak{c} \mathfrak{r} \mathfrak{u} \mathfrak{g} \mathfrak{e}$.}

Seite 4. Zeile 11. บ. น. ftatt hüherer fege fiderer.

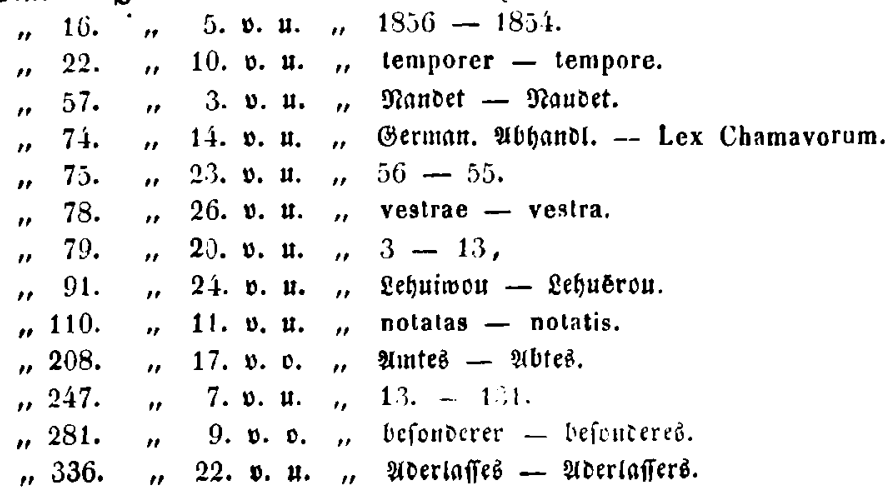

